EDUR • Educação em Revista. 2021; 37:e32746

DOI: http://dx.doi.org/10.1590/0102-469832746

(9) (1) https://creativecommons.org/licenses/by/4.0/

\title{
FORMAÇÃO DOCENTE NA ESCOLA E NA UNIVERSIDADE: CONTRIBUIÇÕES DAS NARRATIVAS (AUTO)BIOGRÁFICAS
}

\author{
INÊS FERREIRA DE SOUZA BRAGANÇA ${ }^{1}$ \\ ORCID: https://orcid.org/0000-0003-4782-1167
}

\begin{abstract}
RESUMO: O presente artigo socializa pesquisa que teve como objetivo refletir sobre concepções e práticas de formação docente, tematizando possíveis contribuições das narrativas (auto)biográficas, no âmbito da formação inicial de professoras/es, desenvolvida no curso de Pedagogia de uma universidade pública do estado de São Paulo, e da formação continuada, no contexto de escolas dos anos iniciais do Ensino Fundamental da região metropolitana, no qual se insere a referida instituição. Foram levantadas as seguintes questões: como se delineiam concepções e práticas de formação inicial e continuada de professoras/es nos contextos de desenvolvimento da pesquisa? Quais as possíveis contribuições da elaboração e partilha de narrativas (auto)biográficas em processos de formação inicial e continuada? $\mathrm{O}$ referencial teórico-metodológico foi tecido no diálogo entre a abordagem de pesquisaformação narrativa (auto)biográfica e os estudos nosdoscom os cotidianos escolares, em um caminho que incluiu um inventário das práticas, memórias e políticas da formação de professoras/es, nos contextos de realização da pesquisa, e desenvolvimento de práticas de formação, ancoradas na abordagem narrativa (auto)biográfica em turmas de estágio supervisionado e nas escolas envolvidas. O desenvolvimento da pesquisaformação reafirma a potência da produção de saberes que se dá, no encontro e no diálogo, entre universidade e escola, bem como o papel das narrativas (auto)biográficas na mediação de um caminho reflexivo de partilha e construção coletiva do conhecimento pedagógico.
\end{abstract}

Palavras-chave: Formação inicial, formação continuada, curso de Pedagogia, narrativas, pesquisa (auto)biográfica.

\section{TEACHER FORMATION IN SCHOOL AND UNIVERSITY: CONTRIBUTIONS OF (AUTO)BIOGRAPHICAL NARRATIVES}

\begin{abstract}
The present article reports on the research that aimed to reflect on conceptions and practices of teacher formation, discussing possible contributions of (auto)biographical narratives in the context of initial teacher formation, developed in the Pedagogy course of a public university in the state of São Paulo, and of continued formation in the context of schools of the early years of elementary education in the metropolitan region where the institution is located. The following questions were raised: how are conceptions and practices of initial and continued formation outlined for teachers in the contexts

${ }^{1}$ Faculdade de Educação da Universidade Estadual de Campinas (FE/UNICAMP). Campinas, SP, Brasil. <inesfsb@unicamp.br>


of research development? What are the possible contributions of the elaboration and sharing of (auto)biographical narratives in initial and continuing education processes? The theoretical and methodological reference was woven in a dialog between the narrative (auto)biographical researchformationapproach and the studies on school everyday life, in a path that included an inventory of the practices, memories and policies of the formation of teachers, in the contexts where the research was carried out, and the development of formation practices, anchored in the narrative (auto)biographical approach in supervised internship classes and in the schools involved. The development of the researchformation reaffirms the power of knowledge production that takes place in the encounter and dialogue between university and school, as well as the role of (auto)biographical narratives in mediating a reflective path of sharing and collective construction of pedagogical knowledge.

Keywords: Initial formation, continued formation, Pedagogy course, narratives, (auto)biographical research.

\section{LA FORMACIÓN DEL PROFESORADO EN LA ESCUELA Y LA UNIVERSIDAD: APORTACIONES DE LAS NARRATIVAS (AUTO)BIOGRÁFICAS}

RESUMEN: El presente artículo describe la investigación que tuvo como objetivo reflexionar sobre las concepciones y prácticas de la formación de profesores, discutiendo las posibles contribuciones de las narrativas (auto)biográficas, en el ámbito de la formación inicial de profesores, desarrollada en el curso de Pedagogía de una universidad pública del estado de São Paulo, y de la formación continuada, en el contexto de las escuelas de los primeros años de la educación primaria en la región metropolitana donde se encuentra la institución. Se plantearon las siguientes preguntas: ¿cómo se perfilan las concepciones y las prácticas de la formación inicial y continua de los profesores en los contextos de desarrollo de la investigación? ¿Cuáles son las posibles aportaciones de la elaboración y puesta en común de las narrativas (auto)biográficas en los procesos de formación inicial y continua? El marco teórico y metodológico se tejióen diálogo entre el enfoque de lainvestigación-formación narrativa (auto)biográfica y losestudios sobre la vida cotidiana escolar, enun recorrido que incluyóun inventario de lasprácticas, memorias y políticas de laformación de losprofesores, enlos contextos de realización de lainvestigación, y eldesarrollo de prácticas de formación, ancladasenel enfoque narrativo (auto)biográfico enlasclases de prácticas supervisadas y enlasescuelas involucradas. El desarrollo de lainvestigación-formación reafirma el poder de producción de conocimiento que se produceenelencuentro y el diálogo entre launiversidad y laescuela, así como el papel de las narrativas (auto)biográficas enlamediación de uncamino reflexivo de intercambio y construccióncolectivadelconocimiento pedagógico.

Palabras clave: Formación inicial, formación continua, curso de pedagogía, narrativas, investigación (auto)biográfica. 


\section{INTRODUÇÃO}

O presente artigo focaliza a formação de professoras $/ \mathrm{es}^{2}$, no âmbito da formação inicial, desenvolvida pela Faculdade de Educação da Universidade Estadual de Campinas (FE/UNICAMP), e da formação continuada, no contexto de escolas dos anos iniciais do Ensino Fundamental. Pautada na abordagem de pesquisaformação $0^{3}$ narrativa (auto)biográfica e nos estudos nosdoscom os cotidianos escolares, dirige o olhar para concepções e práticas de formação, contextualizadas pelas práticas, memórias e políticas, especificamente, do Curso de Pedagogia e das redes públicas de ensino da região metropolitana, onde se insere a referida universidade. ${ }^{4}$

A pesquisa desenvolvida toma, como compromisso político-epistêmico, o entrelaçamento indissociável entre ensino, pesquisa e extensão, bem como a pesquisa feita com a escola e com as/os professoras/es, em uma epistemologia que se assenta na luta por um projeto emancipatório de sociedade e no movimento virtuoso entre palavra e escuta sensíveis. Nesse sentido, perspectiva múltiplos atravessamentos entre as políticas docentes, a produção acadêmica e os saberesfaz̧eres cotidianos, favorecendo a construção de conhecimentos no Curso de Pedagogia e no cotidiano das escolas.

As experiências vividas, por meio do acompanhamento de estudantes em estágio e também do desenvolvimento da pesquisaformação, no diálogo entre universidade e escola, levam ao encontro de um espaçotempo intensamente tomado por demandas, em uma visível intensificação do trabalho docente (OLIVEIRA, 2020). Em estados e municípios que implementaram a Lei do Piso Salarial Profissional Nacional (BRASIL, 2008), o horário de trabalho pedagógico coletivo tem sido, na maioria das vezes, ocupado por atividades que não priorizam a construção de saberes pedagógicos em partilha entre as professoras. Por outro lado, no âmbito da formação inicial, também podemos problematizar de que modo temos favorecido a construção de saberes experienciais que consideram as trajetórias de vida dos estudantes e traduzam o atravessamento entre teorias e práticas.

Tomamos como referência a discussão de saberes docentes, a partir das contribuições de Tardif (2000, p.10), em "um sentido amplo, que engloba os conhecimentos, as competências, as habilidades (ou aptidões) e as atitudes, isto é, aquilo que muitas vezes foi chamado de saber, saber-fazer e saber-ser", incluindo, conforme Gonçalves e Monteiro (2017), dimensões disciplinares, curriculares, pedagógicas e da experiência. Um saber que, sendo amplo, articula diferentes dimensões pessoais, acadêmicas e profissionais.

Nessa perspectiva, Tardif (2000) alerta para desafios importantes: um processo centrado no contexto de trabalho, não confundir saberes profissionais com saberes mobilizados na formação universitária, a valorização dos saberes docentes construídos no cotidiano escolar e na prática pedagógica para a formação de professoras/es. O campo problemático, aqui delineado, aponta para a centralidade de uma formação assentada em saberes outros, fertilizados por encontros e diálogos entre professoras em formação inicial e professoras em atuação nas escolas básicas, por meio da produção e partilha de narrativas pedagógicas.

O uso do feminino tem como referência que, tanto na escola como na universidade, encontramos a significativa presença de mulheres estudantes do Curso de Pedagogia e mulheres professoras dos anos iniciais do ensino fundamental; tomamos, assim, o feminino para demarcar uma concepção político-epistêmica. Louro (2004, p. 393) retoma a história da presença feminina no magistério e tematiza diferentes denominações recebidas que relevam representações da docência como "professorinhas, tias e trabalhadoras da educação". Se, inicialmente, a presença das mulheres deu-se como professorinhas e tias, hoje, reivindicamos o lugar de profissionais e trabalhadoras da educação. Na pesquisaformação desenvolvida, buscamos visibilizar, nas narrativas de estudantes e professoras, as imagens

\footnotetext{
2 Considerando a significativa presença feminina no magistério, em geral, e dos anos iniciais do ensino fundamental, em especial, bem como a centralidade das questões de gênero na problematização histórica, política e epistemológica da formação, optamos por usar "professoras/es" quando nos referirmos a abordagens gerais sobre o campo e apenas pelo feminino quando tratarmos da especificidade da presente pesquisa.

${ }^{3}$ Ao longo do texto, tendo como inspiração e referência os estudos nosdoscom os cotidianos escolares, algumas palavras serão agrupadas e grafadas com itálico, indicando o atravessamento de sentidos e indissociabilidade dos conceitos. (FERRAÇO; SOARES; ALVES, 2017)

${ }^{4}$ Pesquisa financiada pela Fundação de Amparo à Pesquisa do Estado de São Paulo (FAPESP). 
e saberes (res)construídos sobre a docência, ao longo de suas trajetórias de vida e formação.

Tendo como referência esse campo problemático, destacam-se como questões de estudo: como se delineiam concepções e práticas de formação inicial e continuada de professoras/es nos contextos de desenvolvimento da pesquisa? Quais as possíveis contribuições da elaboração e partilha de narrativas (auto)biográficas em processos de formação inicial e continuada? A proposta metodológica incluiu as seguintes dimensões: inventário das práticas; memórias e políticas de formação docente, desenvolvidas na FE/UNICAMP e no cotidiano das escolas; produção coletiva de práticas de formação, no contexto da formação inicial e continuada, em diálogo com a produção acadêmica dirigida à formação de professores/as, com enfoque em abordagens narrativas(auto)biográficas. O presente artigo socializa, a seguir, os caminhos trilhados no desenvolvimento da pesquisaformação, em diálogo com os referenciais teórico-metodológicos; a contextualização dos espaços institucionais; a experiência de trabalho com a abordagem narrativa (auto)biográfica nos contextos de formação e reflexões finais.

\section{SOBRE CAMINHOS TRILHADOS}

A pesquisaformação perspectiva sentidos do processo de formação de professoras/es em sua articulação com a memória e a narração, como abordagens potentes de investigação no campo educativo. Entendemos que, ao mesmo tempo que pesquisamos, nos formamos e que todos os envolvidos, ou seja, pesquisadora, estudantes do Curso de Pedagogia, professoras e professores da escola básica, também, formam e se formam em partilha. Tendo como referência o trabalho pioneiro de Gaston Pineau (2010; 2020) e Marie-Christine Josso (2010; 2020) com a corrente das histórias de vida em formação, tomamos a potência da pesquisa-formação, problematizando a pesquisa para além dos pares ciência/técnica, teoria/prática, apontando para a possibilidade de incorporar, de forma rizomática, experiência/sentido (LARROSA, 2017).

Portanto, não me parece exagero dizer que o conceito de experiência de vida é provavelmente o conceito fundador do nosso paradigma [...]. A experiência, volto a enfatizar, é forjada e construída no lugar da interseção entre a singularidade de cada percurso e a alteridade emergente de todos os cursos compartilhados. (JOSSO, 2020, p.45, 46)

As várias crises ecológicas da atualidade, a aceleração do desenvolvimento profissional e as necessidades de transmissão intergeracional desses sujeitos portadores de humanidade parecem nos convidar para situar essas práticas emergentes em um movimento mais amplo de usos de dispositivos autobiográficos para ancorar, mais explicitamente, políticas de pesquisa-formação em ciências humanas nesses tesouros escondidos da humanidade. (PINEAU, 2020, p.59)

A perspectiva de pesquisa-formação, trabalhada pelos autores nos anos 1990, reatualiza-se, no sentido de dar resposta à vida, em seus desafios socioambientais, profissionais, éticos, fertilizando, nas ciências humanas, tesouros escondidos, experiências de vida, construção de saberes e formação humana. Uma pesquisa que se envolve e se mistura com a vida, ao longo do processo, que entrelaça movimentos indissociáveis de pesquisarformar.

A corrente das histórias de vida, de matriz francesa, chegou ao Brasil pelas preciosas contribuições do professor António Nóvoa (2010) e, aqui, encontra um campo fértil e já fervilhante de práticas de escuta de histórias e registros narrativos de docentes e estudantes, tanto em âmbitos da pesquisa como da formação. Legados de Freire (1992), enredados ao trabalho de professoras/espesquisadoras/es que chegam às universidades brasileiras, vindas da escola básica, como Regina Leite Garcia (2001), Célia Linhares (1996), Nilda Alves (2003), Maria Helena Abrahão (2004). Entre nós, no Brasil e na América Latina, potencializamos a perspectiva narrativa (auto)biográfica, especialmente, no campo dirigido à educação e à formação docente, em particular, por meio de memoriais de formação (ABRAHÃO, 2008; PASSEGGI, 2008), documentaşão narrativa de experiências pedagógicas (SUAREZ, 2011), narrativas pedagógicas (PRADO; CUNHA; SOLIGO, 2008) e narrativas de formação (SOUZA, 2004). Cada dispositivo em sua singularidade, aponta para a potência das narrativas (auto)biográficas tecidas, individualmente ou em grupos, orais, escritas, imagéticas e nos mais diversos suportes. Dessa forma, 
tomamos as narrativas como fonte de pesquisa e movimento de (trans)formação.

A assunção da pesquisaformação implica o compromisso com a produção de um conhecimento científico, potencialmente, (trans)formador para todos os envolvidos ${ }^{5}$, para ações articuladas entre a docência na graduação e na pós-graduação e a produção de um conhecimento implicado com as escolas e com as professoras em ações de pesquisa-formação-extensão. $O$ desenvolvimento da pesquisa, em suas várias etapas, favoreceu a construção de diversas fontes. Os documentos e aportes legais foram organizados e sistematizados e os encontros de pesquisaformação registrados, por meio do diário de itinerância (BARBIER, 2002), tendo em vista movimentos reflexivos, em diálogo com os objetivos da pesquisa e as narrativas de estudantes e docentes produzidas no período de 2017 a $2021^{6}$.

A compreensão das fontes foi desenvolvida, por meio da abordagem cênica, tal como proposta por Marinas (2007). No circuito da palavra dada e escuta, que envolve as narrativas (auto)biográficas, temos acesso a um conjunto de cenas, algumas inacessíveis outras ruidosas, umas visíveis, claras, outras enigmáticas. E, assim, o autor propõe a compreensão cênica como caminho de interpretação em

Que o sujeito se constitui no relato de muitas maneiras e que estas formam uma pluralidade de cenas que são efeitos e condições da linguagem [...]. E logo concluímos com uma dimensão importante que, superando a hermenêutica linear, relaciona sujeito-escuta-produção: a compreensão cênica. (MARINAS, 2007, p. 87)

Nessa perspectiva, a narrativa constitui um "repertório de cenas" e a compreensão é colocada sobre cada cena e na relação, nos jogos estabelecidos entre elas: 1) a cena da enunciação, valorizando o circuito entre palavra dada e escuta; 2) as múltiplas cenas do cotidiano no contexto espaço/temporal do tríplice presente (RICOEUR, 1994), ou seja, um cotidiano não circunscrito ao aqui e agora, mas prenhe da relação entre passado, presente e futuro e 3) as cenas implícitas, ou seja, os não ditos, os silêncios, as pausas. (MARINAS, 2007, p. 118)

Nas palavras do autor:

A compreensão cênica implica entender o relato não como uma história linear, cumulativa, mas como um repertório de cenas. Delas, a primeira (E1) é a que reúne na escuta, o narrador e o entrevistador. [...] As cenas 2 são as que formam parte da vida cotidiana de quem narra, suas posições como emissor e receptor atravessam de volta a cena 1 na medida em que ela se atualiza. Nesse jogo entre as cenas 1 e 2 se dá a possibilidade de passar a emergência das cenas reprimidas ou esquecidas (3). (p.119)

Assim, a interpretação recai sobre as relações e jogos estabelecidos entre as cenas e nos diferentes papéis por elas desempenhados e, sendo um movimento dialógico (BAKHTIN, 2011), é tecido de forma horizontal pelos participantes. $\mathrm{Na}$ leitura das fontes, identificamos pistas para o desenvolvimento dessa abordagem interpretativa. Cada narrativa entretece uma determinada trama, na acepção de Ricoeur (1994), uma síntese do heterogêneo, e a compreensão cênica, a qual busca sentidos das relações entre as tramas de episódios e tempos, personagens e ações, em um convite às múltiplas leituras.

\section{CONTEXTUALIZAÇÃO: POLÍTICAS DE FORMAÇÃO}

A etapa que denominamos contextualização consistiu em levantamento documental sobre a formação inicial de professoras/es no Curso de Pedagogia da Faculdade de Educação da UNICAMP, incluindo estudo de documentos e da legislação. Considerando, como Kramer (1997), o projeto pedagógico de um curso não como um lugar, mas um caminho, uma construção diária e cotidiana

\footnotetext{
${ }^{5}$ No caso, a pesquisadora proponente, os estudantes em formação inicial, estudantes de pós-graduação, bolsistas de iniciação científica e professoras das escolas participantes, em ações realizadas na universidade e nas escolas.

${ }^{6}$ A pesquisaformacão, durante o período de 2017 a 2021, envolveu a participação de cinco escolas públicas e oito turmas de estágio supervisionado. 
daquelas e daqueles que habitam o espaçotempo educativo, no âmbito da formação inicial, questionamos: Quais as especificidades dos caminhos do curso de Pedagogia no estado de São Paulo? Como vem se constituindo na FE/UNICAMP?

O curso da FE teve seu início em 19747, com o objetivo de formar especialistas em educação, com as seguintes habilitações: Orientação Educacional, Administração Escolar e Supervisão Escolar, não contando com a formação docente, nesse momento inicial, só registrada em 1977, com a inclusão da habilitação para as Disciplinas Especializadas do Ensino de $2^{\circ}$ Grau, que contemplava atuação na docência dos anos iniciais de escolarização e na Escola Normal. Temos, desse modo, o início do Curso de Pedagogia da Faculdade de Educação (FE), no contexto do regime militar e do tecnicismo, com foco na formação de especialistas em educação. O currículo era organizado em dois blocos: um núcleo comum a todas as habilitações e um específico, sendo que os estudantes poderiam optar por, no mínimo, uma e, no máximo, duas habilitações (FE/UNICAMP, 2017). Dessa forma, sua história entrelaça-se, diretamente, ao cenário do curso no Brasil, marcado por especializações na década de 1970 e, com a abertura democrática e o movimento dos educadores, a inclusão da docência, como componente central, articulador da formação do pedagogo/a.

No conjunto de diversas reformulações ${ }^{8}$, destaca-se a de 1997, no contexto do intenso movimento dos educadores encaminhados pela Associação Nacional pela Formação dos Profissionais da Educação (ANFOPE), Associação Nacional de Pós-Graduação e Pesquisa em Educação (ANPED), Fórum Nacional de Diretores de Faculdades, Centros de Educação ou Equivalentes das Universidades Públicas Brasileiras (FORUMDIR) e outras entidades, na direção de formar o professor e o especialista no professor; nesse sentido, foram incorporados os seguintes princípios: "a docência como base da formação, a formação teórica sólida e interdisciplinar, não fragmentada em habilitações, o eixo da pesquisa, a criação dos núcleos temáticos, a organização curricular por módulos bimestrais; o compromisso ético e político com a escola pública" (FE/UNICAMP, 2017, p.18). Esse currículo materializava, em seus princípios e em sua organização curricular, o movimento pela formação de professores, defendida, especialmente, pela ANFOPE.

Em âmbito nacional, após a Lei de Diretrizes e Bases da Educação Nacional (BRASIL, 1996), iniciou-se um longo período de discussão sobre a formação docente e o Curso de Pedagogia que, depois de muitas reelaborações, teve publicadas as Diretrizes Curriculares Nacionais, em 2006. A partir da sua publicação, os cursos iniciaram processos de reformulação. É importante destacar que as referidas Diretrizes consubstanciaram múltiplas tensões, sendo forte a presença dos princípios construídos pelo movimento dos educadores, desde a década de 1980, dentre os quais, a centralidade da docência como base da formação, a articulação entre a formação para docência e gestão e a atuação do pedagogo em espaços escolares e não-escolares.

Na FE/UNICAMP, após 10 anos da reformulação realizada em 1997, o conjunto de professores, em diversos Seminários e avaliações, passaram a discutir o curso, tendo em vista uma reformulação que atendesse às Diretrizes, mantendo princípios e delineamentos da Faculdade. O novo currículo foi aprovado e entrou em vigor em 2008. O caminho trilhado em sua construção por estudantes e docentes, foi sistematicamente avaliado, apontando para um conjunto de revisões delineadas no currículo de 2015. Essas revisões atenderam, também, a Deliberação CEE/SP 111/2012, alterada pela Deliberação CEE/SP 126/2014, que fixou "Diretrizes Complementares para a Formação de Docentes para Educação Básica nos Cursos de Graduação de Pedagogia, Normal Superior e Licenciaturas, oferecidos pelos estabelecimentos de ensino superior vinculados ao sistema estadual".

É flagrante a interferência direta do Conselho Estadual Educação dirigida à formação de professores sob a responsabilidade das universidades estaduais paulistas. Em artigo escrito pelas professoras Adriana Varani, Dirce Zan e Luciene Grandin (2018, p.11), as autoras destacam criticamente essa interferência, limitando o direito constitucional de autonomia universitária: "ao retomarmos esse

\footnotetext{
${ }^{7}$ Foi em 1973 que o Prof. Marconi Freire Montezuma, chefe do Departamento de Educação, solicitou ao Reitor Zeferino Vaz a autorização para implantação do Curso de Pedagogia da Faculdade de Educação, ressaltando "a importância do referido curso para a formação de especialistas para a educação” (COUTINHO, 2002, p. 70 apud FE/UNICAMP, 2017, p. 17).

${ }^{8}$ Inclusão de habilitações (1979) e alteração da carga horária dos estágios (1984).
} 
debate sobre a autonomia universitária, salta aos olhos a postura do CEE/SP de afronta ao texto constitucional. O Conselho tem se colocado como o mandatário da organização curricular nas universidades públicas, desconsiderando possibilidades de diálogo e negociação". A Deliberação CEE/SP 111/2012, alterada pela 126/2014, considera que há uma lacuna na formação escolar dos licenciandos que deve ser superada na universidade de forma compensatória, havendo, ainda, uma compreensão de separação entre conteúdo e método, indicando a revisão dos currículos e enfatizando, especialmente, a metodologia, o "como ensinar". Em 2017, a Deliberação foi novamente alterada, incluindo horas de Prática como componente Curricular (PCC), trazendo mais uma vez a necessidade de ajustes na matriz curricular, tendo em vista o atendimento das exigências do Conselho Estadual. (VARANI; ZAN; GRANDIN, 2018)

$\mathrm{Na}$ continuidade dos movimentos de avaliação/reorganização do curso, vivemos momentos instituintes, com seminários realizados nos anos de 2018 e 2019, com reflexões, que trouxeram, à tona, princípios de formação docente, como a crítica à perspectiva tecnicista/neotecnicista e, consequentemente, da prática como aplicação. Tendo como referência as discussões e questionamentos do Seminário, bem como a pesquisa com os cursos de Pedagogia do Rio de Janeiro (BRAGANÇA, 2014), Larrisa Ré realizou levantamento das propostas pedagógicas e matrizes curriculares de universidades públicas paulistas, a saber: Universidade de São Paulo (USP), Universidade Estadual de Campinas (UNICAMP), Universidade Estadual Paulista "Júlio de Mesquita Filho" (UNESP), Campus Marília e Bauru, Universidade Federal de São Carlos, Campus Sorocaba e Universidade Virtual do Estado de São Paulo (UNIVESP). Quanto aos estágios, foi possível verificar que:

Do ponto de vista da carga horária, a UNICAMP possui a maior entre todas as universidades analisadas com um total de 3.825 horas. [...]

O estudo da carga horária dos estágios obrigatórios também é fundamental. Enquanto a UNICAMP possui $630 \mathrm{~h}$ de estágio supervisionado, levando em conta a prática, teoria e orientação do docente, as outras universidades possuem entre 400 e 450h. (RÉ, 2020, p. 30)

Quanto à distribuição das disciplinas, o campo dos fundamentos da educação apresenta treze disciplinas - o maior número dentre os cursos pesquisados, as disciplinas de didática e metodologia seis - o menor número comparativamente - e, no que se refere aos conhecimentos relativos às modalidades e etapas de ensino específicas - educação infantil, na educação especial e na educação de jovens e adultos - cinco disciplinas.

É nítida a importância dada às disciplinas teóricas pela FE/UNICAMP, o que denota por um lado a busca por uma formação emancipatória, crítica e reflexiva e que considera as múltiplas dimensões do sujeito e da docência, entretanto, por outro deixa em segundo plano as práticas pedagógicas. Considerando que a $\mathrm{FE}$ passa por um processo de reformulação do curso, perspectivamos que a discussão coletiva possa indicar um delineamento curricular que aponte para o equilíbrio entre as diversas áreas e dimensões, bem como o necessário atravessamento entre teorias e práticas. (RÉ, 2020, p. 31)

Dando continuidade às discussões, foi constituído um Grupo de Trabalho para a reformulação do curso, mas os cenários políticos tornaram-se cada dia mais sombrios, tensos. Ataques à educação pública e à universidade fizeram-se cada dia mais fortes. Em dezembro de 2019, fomos surpreendidos com a publicação de "novas" Diretrizes Curriculares Nacionais para a Formação Inicial de Professores da Educação Básica, que instituiu, também, a Base Nacional Comum para a Formação Inicial de Professores da Educação Básica (BNC-Formação) (BRASIL, 2019). As Diretrizes de 2015 (BRASIL, 2015) que contaram com ampla discussão dos profissionais da educação, juntamente com suas associações representativas, foram substituídas por uma resolução sem a participação coletiva, atrelando, de forma linear, a formação de professores à implementação da BNCC.

No mesmo contexto, o Conselho Nacional de Educação (CNE) iniciou a revisão das Diretrizes Curriculares Nacionais do curso de Pedagogia, emitindo uma proposta preliminar que descaracteriza o curso constituído pelas Diretrizes de 2006, bem como as conquistas do movimento dos educadores quanto a ter na docência a base em uma formação ampla, articulada à gestão educacional. A 
proposta apresentada pelo CNE fragmenta a formação para docência da educação infantil, dos anos iniciais e gestão, em um retrocesso explicitado pela ANFOPE, em documento enviado ao Conselho, em fevereiro de 2021 (ANFOPE, 2021).

No âmbito social e político, sofremos ataques abertos e deliberados à educação pública, pelo governo federal e, também, estadual, com clima de cerceamento à liberdade de cátedra e acirramento do contingenciamento financeiro. Os anos de 2020 e 2021, marcados pela pandemia da Covid 19, trouxeram, à tona, as graves injustiças sociais, a desigualdade de condições de vida, de saúde e de acesso aos recursos tecnológicos que se tornaram ainda mais indispensáveis no contexto de isolamento social. $\mathrm{Na}$ escola e na universidade, foi preciso empreender movimentos de luta pela vida e pela continuidade dos processos formativos possíveis. Sobre os estágios foram intensas e profícuas as reflexões e deliberação coletivas, acompanhando o contexto de agravamento das crises sanitária e política.

$\mathrm{Na}$ formação continuada, destaca-se, em uma dimensão, o intenso movimento dos profissionais da educação, no reconhecimento da escola e das práticas sociais como espaçostempos formativos e, em outra, o amplo aparato legal brasileiro constituído, especialmente, a partir da Constituição Cidadã de 1988, no incentivo à formação continuada. Desde os anos 1980, observamos uma mobilização que envolve pesquisa e formação com as escolas, na assunção desta como locus de produção dos saberes pedagógicos. Trabalho desenvolvido em diferentes regiões brasileiras que vem reverberando em múltiplas formas de atuação, envolvendo a formação continuada docente centrada na escola.

A Lei de Diretrizes e Bases da Educação Nacional (BRASIL, 1996) tornou a formação continuada direito dos profissionais da Educação Básica e os Planos Nacionais de Educação de 2001 e de 2014 (BRASIL, 2001; 2014) reafirmaram e definiram metas específicas para a garantia deste direito. A meta 16 do PNE vigente (BRASIL, 2014) destaca a garantia "a todos (as) os (as) profissionais da educação básica formação continuada em sua área de atuação, considerando as necessidades, demandas e contextualizações dos sistemas de ensino" (BRASIL, 2014, p. 51). Na mesma esteira, as "Diretrizes Curriculares Nacionais para a formação inicial em nível superior (cursos de licenciatura, cursos de formação pedagógica para graduados e cursos de segunda licenciatura) e para a formação continuada" (BRASIL, 2015, p. 8, grifo nosso), definem a necessária articulação entre os centros de formação de todos os entes federados, o Sistema Nacional de Avaliação da Educação Superior (Sinaes), a educação básica, em suas políticas e diretrizes e o Projeto Pedagógico de Formação Continuada (PPFC). (BRASIL, 2015, p. 3).

$\mathrm{Na}$ recuperação dos documentos e acompanhamento das discussões internas da FE/UNICAMP, destaca-se a importância do diálogo entre universidade e espaços formativos, tomando a relação com a escola pública como foco prioritário para as práticas de estágio. O livro organizado pelas professoras Maria Inês Petrucci-Rosa e Dirce Zan (2015) traz uma importante contribuição para a história da formação de professores na FE. Além de textos escritos, a partir de um ciclo de debates realizado com docentes e alunos, inclui a preciosidade da transcrição literal de um texto datilografado, "redigido há cerca de duas décadas", sobre os estágios das Licenciaturas. Conforme o fragmento a seguir, percebemos a preocupação central entre a UNICAMP e a escola.

Um aspecto importante, evocado pela legislação, que justificou a passagem dos estágios dos Colégio de Aplicação para as Escolas da Comunidade, foi a necessidade de vincular as escolas formadoras dos professores às escolas da rede comum, onde esses professores iriam futuramente lecionar. O Estágios Supervisionados seriam a via através da qual se promoveria a pretendida integração. O Estágios seriam um elo de comunicação entre as escolas de nível médio e aquelas de nível superior. Por um lado, deveriam permitir ao ensino superior conhecer mais de perto os problemas educacionais existentes nos níveis de ensino anteriores. Por outro lado deveriam possibilitar à escola de ensino médio a atualização em relação aos conhecimentos específicos e pedagógicos produzidos no nível superior, conhecimentos esses que poderiam servir como fonte de melhoria e renovação do ensino nela praticado. (CAMARGO; FRACALANZA, 2015, p. 25)

Documentos, seminários e discussões seguem reafirmando a centralidade da escola na formação docente, incentivando o diálogo, as parcerias e convênios com as redes públicas de ensino, conforme expresso na política de estágio (FE, 2008). 
Tomando a centralidade do conceito de práxis como possibilidade de compreensão da realidade, para além da dimensão teórica e prática, mas também política, técnica, de experiência e de sentido, incluindo práticas culturais, experimentações e linguagens (GRAMSCI, 1991; BENJAMIN, 1993), ao perspectivar o desenho curricular, não teríamos um conjunto de disciplinas teóricas e outras práticas, em sequência linear, todas seriam práticas-teórico-ético-estético-políticas, em uma imagem complexa. Nesse contexto, insere-se a pesquisaformação, aqui partilhada, perspectivando o adensamento do diálogo entre universidade e escola, formação inicial e continuada.

\section{NARRATIVAS NA ESCOLA E NA UNIVERSIDADE}

Em um projeto financiado, inicialmente pela Fundação de Desenvolvimento da UNICAMP (FUNCAMP), e, posteriormente, pela Fundação de Amparo à Pesquisa do Estado de São Paulo (FAPESP), foram iniciados, em 2017, movimentos de aproximação das escolas e, em 2018, juntamente com professores de estágio dos anos iniciais, construímos um diálogo mais efetivo. A proposta consiste em encaminhar os estudantes para realização do estágio em um conjunto de escolas parceiras, que recebem os estagiários e se envolvem no projeto de pesquisaformação, as estagiárias, em formação inicial, e as professoras, em formação continuada. As estudantes produzem registros narrativos, ao longo do semestre, socializados, oralmente e por escrito, em encontros realizados na universidade, no horário das aulas de estágio, e nas escolas, nos horários de trabalho pedagógico coletivo, favorecendo a visibilidade de imagens da docência e saberes (re)construídos, ao longo da trajetória de vida e formação, por estudantes do curso de Pedagogia e professoras dos nos iniciais do ensino fundamental. ${ }^{9} 10$

A formação continuada de professores apresenta um amplo suporte legal, cujo destaque, considerando o escopo do presente artigo, é a Lei do Piso Salarial Profissional Nacional para os profissionais do magistério público da Educação Básica (PSPN) (BRASIL, 2008), anteriormente mencionada, que, além de fixar um vencimento base com ajuste anual, considerando uma carga horária de quarenta horas semanais, define o limite de dois terços do tempo para o trabalho com os estudantes e um terço para planejamento, estudo e avaliação, ou seja, para o trabalho extraclasse ${ }^{11}$. A implementação da lei deu-se das formas mais diversas pelos estados e municípios. Em São Paulo, a Resolução SE 72, de 16-12-2019 $9^{12}$, definiu que:

Artigo $1^{\circ}$ - A jornada de trabalho docente é constituída de aulas com alunos, Aulas de Trabalho Pedagógico Coletivo - ATPC e Aulas de Trabalho Pedagógico em Local de Livre Escolha - ATPL.

$\int 1^{\circ}$ - Entende-se por ATPC aquelas aulas que se destinam a reuniões ou outras atividades pedagógicas, preferencialmente para formação e estudo, de caráter coletivo, bem como para atendimento a pais de alunos;

$\int 2^{\circ}$ - Entende-se por ATPL aquelas aulas que se destinam à preparação de aulas e avaliação dos trabalhos dos alunos.

\footnotetext{
${ }_{9}^{9}$ Trabalho desenvolvido coletivamente pelos professores que atuam na área de estágio: a pesquisadora proponente do projeto, as professoras Adriana Varani, Ana Lúcia Guedes Pinto, Juliana Rink e o professor Guilherme do Val Toledo Prado do Departamento de Ensino e Práticas Culturais (DEPRAC).

${ }^{10}$ No presente artigo, damos ênfase à produção das estudantes sobre seus processos formativos, publicizados por meio de narrativas de estágio e de Trabalhos de Conclusão de Curso. Optamos por não trazer as narrativas das professoras, considerando outras publicações e os limites do artigo.

11 O Parecer n. 09 do CNE (BRASIL, 2009) especifica a organização do tempo de trabalho extraclasse, definindo sua distribuição entre o Horário de Trabalho Pedagógico Coletivo (HTPC) e Horário de Trabalho Pedagógico em Local de Livre Escolha pelo docente (HTPLE).

${ }^{12}$ A Resolução n. 76 de 2020, alterou a Resolução SE 72, de 16-12-2019, que dispõe sobre a carga horária dos docentes da rede estadual de ensino, definindo para uma jornada de trabalho de 40h semanais, 32 aulas de 45 minutos com alunos, 7 Aulas de Trabalho Pedagógico Coletivo (ATPC) e 14 de Aulas de Trabalho Pedagógico Livre (ATPL). (SME CAMPINAS, 2019; 2020)
} 
O município de Campinas, também, organizou-se para atender à Lei do Piso, distribuindo a jornada de trabalho docente entre tempos de Trabalho Coletivo Docente (TDC), Trabalho Docente Individual (TDI), Carga Horária Pedagógica (CHP) e Hora Projeto (HP). O TDC é o tempo de trabalho comum entre os professores da escola, favorecendo o encontro e a construção coletiva, entretanto, como vemos também em outras redes de ensino, "torna-se cada vez mais insuficiente para proporcionar tempo/ espaço para o confronto de ideias e problematizações necessárias para maior qualidade do trabalho coletivo" (GODOY, 2012, p.12).

Nos encontros que realizamos, nas escolas estaduais e municipais da Região Metropolitana de Campinas, o trabalho foi desenvolvido nos ATPC e TDC e as experiências com o tempo, as mais diversas.

Os momentos de formação proporcionam uma pausa no cotidiano para que os professores consigam refletir e buscar alternativas para os problemas que os afligem em sala de aula. Larrosa (2001) discute a necessidade de parar para olhar, para pensar e escutar. (RÉ, 2020, p.51)

Tempo cronometrado de cinquenta minutos entre as muitas demandas de organização do trabalho pedagógico, informes, pouco espaço para reflexão; tempo alargado em uma tarde com leituras, reflexões, lanche coletivo, narrativas partilhadas. Em alguns momentos, tivemos dificuldade de manter o cronograma dos encontros, pois as escolas estavam envolvidas com a intensidade de tarefas das avaliações externas e, assim, seguimos nas brechas de tempoespaço. No início do semestre pude participar de um desses encontros com o tema Escrita de narrativas
docentes, realizado em uma EMEF ${ }^{13}$, uma escola com professores muito especiais. Todos
puderam falar um pouco sobre sua experiência nessa escola, suas memórias, seus processos
formativos, passados e atuais, e nenhum deles deixou de mencionar o acolhimento dos
professores da escola quando chegaram e o companheirismo muito forte entre todos da equipe.
Uma professora apresentou alguns trabalhos desenvolvidos juntamente com suas turmas e fez
uma fala muito bonita sobre a relação de troca entre professor e estudantes no cotidiano da
escola, "Quando a gente se propõe a aprender com eles, nos expandimos. Eu aprendi filmagem, edição de vídeo
e texto. [...] Não sou professora, sou equilibrista de pratos". Outra professora que sempre teve o hábito
do registro falou, incentivando aos demais, que as escritas de sua prática a formaram e continuam
formando, pois ela encara a escrita da narrativa como processo de se olhar e se avaliar, ação-
reflexão-ação". (MEDEIROS, 2019, p.5)

Em resumo, o encontro foi importante para analisarmos a história da escola no coletivo e compreender que dentro de um sistema educacional há muito mais que conteúdo e burocracia. Há o desejo de estar ali, a preocupação com o aluno e uma construção cultural. Para finalizar a reunião, foram lidos dois textos: "O esforço reflexivo de fazer da vida uma história" de Antonio Bolívar e "Pipocas Pedagógicas: uma possibilidade de narrar o vivido na escola" do professor Guilherme do Val Toledo Prado e outros autores. A discussão terminou com as seguintes frases: "Temos pipocas todos os dias na escola", "Você precisa se olhar e depois se mostrar para o outro". Essa é a realidade docente: o compartilhamento de narrativas diárias entre os profissionais da educação. (RÉ, 2020, p.51).

Tomamos, assim, os encontros como espaçostempos potentes de atravessamentos entre práticas de ensino, pesquisa e extensão, considerando, além da presença das estudantes e professoras, a construção dialógica de saberes entre universidade e escola básica. O foco consistiu na partilha sobre prática docente, nas experiências de estágio e formação. Os registros feitos por meio de diários de itinerância (BARBIER, 2002), de narrativas e pipocas pedagógicas (PRADO; PROENÇA; SERODIO; FILHO, 2017), por estudantes, professoras da escola, da universidade e bolsistas de iniciação científica.

Quando estamos juntos, professoras da escola e da universidade e estudantes, "expandimos" o olhar, as reflexões, as ações e, assim, fazemos mais e melhor. Estudamos, partilhamos fazeres, dúvidas, inquietações e a escola coloca-se como espaçotempo singular de culturas e histórias tecidas coletivamente. As "pipocas pedagógicas" são crônicas sobre o cotidiano escolar, desenvolvidas como dispositivo

${ }^{13}$ Escola Municipal de Ensino Fundamental. 
formativo pelo Grupo de Estudos e Pesquisas em Educação Continuada (GEPEC), pequenos textos que condensam saberes e fazeres docentes. Conforme narrativa de Larissa Ré, após a leitura de algumas pipocas, as professoras reconhecem que o cotidiano escolar é cheio delas.

O desenvolvimento da pesquisaformação leva-nos a reafirmar a presença das mulheres professoras na docência das infâncias, sendo o que observamos nas turmas da graduação em Pedagogia e nas escolas, onde fazem estágio. A história da formação de professores/as no Brasil encaminha-nos ao encontro do processo de feminização da docência, especialmente, das infâncias. Vilela (1992) estuda a fundação da primeira Escola Normal, criada na Província do Rio de Janeiro, em 1835, sendo interessante destacar que a primeira turma dessa escola de formação foi constituída apenas por homens; ao longo do século XX, entretanto, observamos abertura ao ingresso feminino. Demartini e Antunes tematizaram o magistério primário como profissão feminina e carreira masculina, retomando, por meio de relatos orais, a trajetória de professoras e professores paulistas "que se formaram e lecionaram em escolas primárias nas primeiras décadas" do século XX. As narrativas indicam que, na história dos professores homens, o magistério primário consistiu em campo de passagem em direção a cargos de gestão escolar e do sistema, enquanto as mulheres permaneceram na sala de aula (DEMARINI; ANTUNES, 1993, p.9).

Yuki Matsuguma reflete sobre o modo como a graduação em Pedagogia contribuiu no processo de reconhecimento da sua posição no mundo, como mulher nipo-brasileira.

\begin{abstract}
Como uma mulher brasileira com descendência japonesa, fui atravessada tanto pelos padrões estéticos e de comportamento brasileiros quanto japoneses, que se encontram em alguns aspectos, mas se diferenciam em outros. Durante meus estudos para esta pesquisa, juntamente às discussões realizadas em aula, entendi que o que se espera de uma mulher está estritamente atrelado à condição social em que ela se enquadra. Se enquanto de uma mulher branca são esperadas a maternidade, fragilidade, beleza, delicadeza, e a dependência por uma relação com um homem, a expectativa sobre as mulheres negras está relacionada à força, resistência, coragem e os extremos: ou a "hipersexualização da mulata exportação" ou a "dessexualização das mulheres retintas". Já em relação a nós, orientais, a sociedade espera que sejamos quietas, submissas, obedientes, disciplinadas, gentis, "fofas" e preparadas para servir e agradar os outros. Além destas características, outros componentes que se enquadram neste perfil ideal de mulher são: a maternidade e o casamento (heterossexual).[...]

Com base nas minhas experiências e compreendendo as relações de poder e opressões estruturantes da sociedade, me questionei sobre a minha responsabilidade como uma educadora racializada no Brasil. O conhecimento e estudo da perspectiva, mais especificamente, da pedagogia decolonial me auxiliou na elaboração do que para mim seria uma prática docente consciente de todas estas questões sociais e capaz de proporcionar às crianças uma formação ao mesmo tempo, menos preconceituosa e violenta, e mais crítica e transformadora. Além disso, o estudo sobre a decolonialidade me proporcionou reconhecer um outro grande potencial proporcionado pelas narrativas, uma vez que as opressões na sociedade atuam não só de forma explicitamente violenta - como quando "balas perdidas" encontram crianças negras nas favelas - mas de forma sutil com neutralizações e apagamentos. (MATSUGUMA, 2020, pp. 96; 100)
\end{abstract}

Cobranças, padrões estéticos, comportamentais apresentam-se em tensões e disputas nos processos formativos docentes na universidade e no chão da escola. Nesse sentido, a dimensão feminina na formação aponta para a necessidade de afirmação das diferenças, na escuta sensível e na produção de saberes outros. A abordagem narrativa (auto)biográfica tem, em sua própria trajetória epistêmica, a valorização da escuta de vozes e histórias mínimas, traz a contribuição militante das histórias de vida, reivindicando uma nova epistemologia de investigação e de formação. Assim, trazemos, para pesquisa, a dimensão de uma epistemologia presente nos modos de ser e estar na docência de estudantes em formação e professoras da educação básica, as histórias das/os professoras/es que falam da profissionalidade, das práticas, das carreiras.

A continuidade da pesquisaformação, no ano de 2020, nos ensinou, mais uma vez e de forma impensável, o quanto "viver é sempre muito perigoso" (ROSA, 2006), nos (des)caminhos do projeto fomos tomados pela pademia da Covid19, crise política e sanitária sem precedentes; em luto profundo, seguimos. As dores e as dúvidas nos tomaram, enquanto o tempo institucional parecia seguir acelerado na universidade e nas escolas: "aulas" por meio remoto, reuniões on-line, horários, cobranças e controle, interação com os estudantes, por meio de plataformas, busca incansável de contato com estudantes e 
suas famílias. Intensificação do trabalho docente, da vida de professoras-mães nas escolas e na universidade, na produção de novas rotinas de trabalho em casa, acompanhamento de filhos em idade escolar, demandas domésticas e de cuidados com a saúde. ${ }^{14}$

Em 2020, no curso de Pedagogia, realizamos estágios apenas para os formandos de forma remota, buscando a preservação da vida e a continuidade dos processos formativos possíveis.

\begin{abstract}
Essa narrativa de estágio foi uma das mais difíceis do meu percurso acadêmico, em outros estágios a escrita fluía, as crianças do infantil e do fundamental davam a tônica da escrita, os casos, as experiências partilhadas pareciam que pulavam das ideias para o "papel". Neste ano pandêmico, que marcou nossas vidas de formas definitiva e nos fez procurar e reinventar novas formas de interação, o campo do estágio foi uma experiência única que não se encaixa no pensamento binário bom/ruim, o que me fez sentir em diversos momentos um vazio. Como é possível dizer que fiz o estágio sem ter tido uma interação direta com as crianças? (MARTINS, 2021, p.1)
\end{abstract}

Para seguir com as escolas, nos disponibilizamos à continuidade dos encontros, agora, de forma remota e realizamos atividades para partilha das experiências de trabalho docente no contexto pandêmico. Em uma das escolas estaduais, a proposta foi a realização de um sarau, entramos no movimento, produzindo vídeos, fazendo convite à poesia e à música como forma de conhecimento, resistência e reinvenção.

[...] senti que o projeto sarau rompeu com alguns desses paradigmas. Durante toda a construção das etapas do projeto, procuramos, eu e as professoras, nos colocar no lugar das crianças e de suas famílias. Procuramos elaborar propostas abertas, livres e que dialogassem com diversas formas de manifestar o saber: expressão corporal, desenhos, textos, interpretações, pesquisa, oralidade. E, acima de tudo, consideramos as limitações e potencialidades de desenvolver um projeto remoto, virtual. Com isso, deslocamos o "lugar do saber", convidando as crianças e suas famílias a construírem o conhecimento. (NOVO, 2021, p. 3)

Os encontros presenciais e, também, os remotos, expandem a experiência de estágio como tempo de deslocamento no processo formativo, do cotidiano da sala de aula para outros espaços da escola, dando a ver/sentir atravessamentos de concepções e práticas docentes, bem como os desafios do trabalho docente nas redes públicas de ensino. Como vemos na narrativa de Yuki, que fez toda a sua trajetória em escola privada e teve com o estágio o primeiro contato com a escola pública e com o trabalho docente nesse contexto.

Karina Yuki Matsuguma, 21 anos, estudante de Pedagogia da UNICAMP e, portanto, leitora de muito conteúdo sobre a educação brasileira. Fui para o estágio como essa pessoa e, hoje, depois de cinco dias de ida à escola, sei que o "muito" que eu sabia sobre a educação brasileira era quase nada e sobre a realidade dos brasileiros, então, muito menos". [...]

Esta disciplina foi, claramente, o maior desafio que enfrentei até hoje na minha graduação. Com uma ideia totalmente utópica do que é a educação e a escola pública brasileira, eu fui para o meu primeiro estágio. Desde o início me senti deslocada e não pertencente àquela realidade, todos os dias eram novos choques, impactos que me faziam questionar sobre minha escola, sobre o curso de Pedagogia e muitas vezes sobre a minha vida. (MATSUGUMA, 2020, p.42)

Os choques que viveu, dúvidas, questionamentos foram partilhados de forma oral e escrita nos encontros de estágio realizados na universidade, juntamente com as das demais colegas. A tessitura de falas e modos de viver e construir o conhecimento com a escola vai fazendo do estágio um componente curricular, cuja formação dá-se como tessitura de intrigas (RICOEUR, 1994; BRAGANÇA, 2012), fios narrativos dos saberes construídos nas disciplinas do curso de Pedagogia, nas trajetórias pessoais e, no campo de estágio, vão se articulando, compondo sentidos, uma história que pode ser seguida, compreendida, partilhada. Ricoeur (1994) apresenta a narrativa como "arte de compor intrigas",

\footnotetext{
${ }^{14}$ No período pandêmico, reafirmamos os princípios, tomando como prioritária a defesa da vida, assim a realização de estágios apenas remotos e, preferencialmente, em escolas públicas. 
por meio de uma tríade mimética: o campo da ação, das experiências e vivências, a configuração da experiência por meio da narrativa e a recepção pelos leitores com abertura a múltiplas interpretações e novas experiências, narrativas e leituras, um movimento aberto, tendo, na vida e na ação humana, o seu sentido.

\section{REFLEXÕES}

Ao tematizar a vida, contando histórias da formação na universidade e na escola, o desenvolvimento da pesquisaformação levou-nos a deslocamentos, produziu paradas, quedas, retornos, reflexividade (auto)biográfica. Neste último fio do texto, partilhamos reflexões sobre as aprendizagens e lições.

Ao retomar as questões de estudo, podemos afirmar que encontramos, nos cotidianos das escolas e da universidade, as mais diversas concepções e práticas de formação. As institucionalizadas que demarcam o tempo, por exemplo, no âmbito da formação continuada, um terço da jornada de trabalho docente às dinâmicas extraclasse, incluindo a formação, e, na formação inicial, a carga horária de 3.825 horas do curso de Pedagogia. Espaçotempo formal, instituído. Vivemos, entretanto, como sujeitos praticantes dos currículos e da vida, encontros nos corredores, nos pátios das escolas; na cantina e no gramado da FE, muitas assembleias do movimento estudantil e, nesses encontros e conversas, resistência, reinvenção da formação e da profissão pulsam e se expandem. No início do século XX, Benjamin (1993) já alertava sobre as dinâmicas aceleradas que dificultam o encontro, as experiências, as narrativas e nós vivenciamos tais dificuldades. Em uma reunião de ATPC, com tempo marcado de cinquenta minutos, fizemos a leitura de um texto de Paulo Freire e abrimos uma roda de conversa sobre como nos fazemos professoras. No final do encontro, uma professora mencionou que, há muito tempo, não tinham um momento de reflexão partilhada e a potência produzida pelo trabalho coletivo.

Movimentos de reprodução dos materiais didáticos, de transposição linear para a prática docente e, assim, o tempo cronometrado do trabalho pedagógico para corresponder aos conteúdos de cada ano escolar, algumas vezes, dificultando a participação propositiva das estagiárias que se veem reféns do trabalho focado nos conteúdos que estão sendo trabalhados. Mas, testemunhamos, também, a produção de táticas (CERTEAU, 1988) - docentes que desenvolvem projetos coletivos, organizam-se em grupos de estudo sobre a Pedagogia Freinet, realizam ateliês, livros da vida, escrita livre com os estudantes, que fazem seminários internos para a partilha com colegas que trabalham em diferentes turnos, segmentos e modalidades - anos iniciais e anos finais, educação de jovens e adultos, educação especial - as práticas realizadas em uma formação em partilha. Vemos, assim, concepções-práticas instituídas e instituintes de formação, não de modo binário, linear, mas como permanente tensão presente nos cotidianos, em um entrelaçamento complexo.

Com a pandemia, os espaçostempos institucionalizados que já vinham em ritmos intensos, tanto na universidade como na escola, seguiram intensificando o trabalho. A vida e o luto que, hoje atravessamos, impõem a experiência do tempo aion, tempo ilimitado dos sentidos para incluir choro, acolhida, reinvenções. Na escola e na universidade acompanhamos, juntamente com os desdobramentos da pesquisaformação, uma imagem, ao mesmo tempo, forte e sensível das professoras e do seu trabalho. Tanto antes e mais ainda durante a pandemia, se fazer professora/professor implica mobilizar saberes, resistir a movimentos de reprodução, abrir espaço para muitos outros entrarem em nossas histórias.

Nesses espaçostempos de formação, a possibilidade de narrar a vida, as práticas e a profissão, potencializa brechas para construção partilhada do conhecimento pedagógico. A narrativa oral e escrita, tanto das professoras, como das estagiárias, favoreceu uma parada do tempo cronológico e a reflexividade (auto)biográfica sobre as práticas e desafios cotidianos. Nos encontros entre as estagiárias e professora, na universidade, a leitura das narrativas produzidas favoreceu uma orientação horizontal e coletiva e a produção de saberes pedagógicos que entrelaçam, em tessitura, experiências pessoais, conteúdos trabalhados ao longo da graduação e as situações vividas no cotidiano da escola.

Ao partilhar um fragmento da prática docente, um lampejo sobre a formação, é da vida que estamos falamos e escrevendo, vida e profissão entrelaçam-se. A pesquisa narrativa é, assim, especialmente, (auto)biográfica e o (auto)biográfico manifesta-se narrativamente. A retomada dos 
caminhos percorridos reafirma a potência da produção de saberes que se dá no encontro e no diálogo entre universidade e escola, bem como o papel das narrativas (auto)biográficas na mediação de um caminho reflexivo de partilha e construção coletiva do conhecimento pedagógico.

\section{REFERÊNCIAS}

ABRAHÃO, Maria Helena Menna Barreto (org.). A Aventura (Auto) Biográfica - teoria e empiria. Porto Alegre: EDIPUCRS, 2004.

ABRAHÃO, Maria Helena Menna Barreto. Metamemória-memórias: memoriais rememorados/narrados/refletidos em Seminário de Investigação-Formação. In: PASSEGGI, Maria da Conceição; BARBOSA, Tatyana Mabel Nobre (Orgs.). Memórias, memoriais: pesquisa e formação docente. São Paulo: PAULUS; Natal: EDUFRN, 2008, p. 153-179.

ALVES, Nilda. Sobre movimentos das pesquisas nos/dos/com os cotidianos. Teias: Rio de Janeiro, ano 4, no 1-8, jan/dez 2003, p.1-8.

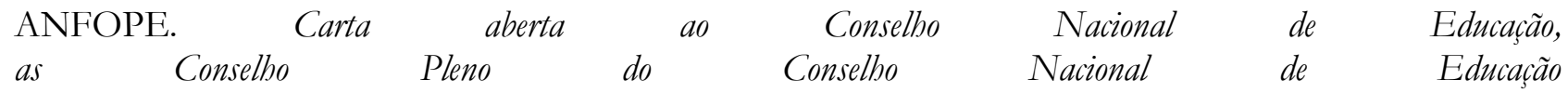

e à Comissão Bicameral do Conselho Nacional de Educação que trata da Revisão das Diretrizes Curriculares Nacionais do curso de Pedagogia. Brasília, 2021.

BAKHTIN, Mikhail. Estética da criação verbal. 6ª Edição. São Paulo: Editora WMF Martins Fontes, 2011.

BARBIER, René. A pesquisa-ação. Brasília: Plano Editora, 2002.

BRAGANÇA, Inês Ferreira de Souza. Histórias de vida e formação de professores/as: diálogos entre Brasil e Portugal. Rio de Janeiro: EdUERJ, 2012. Disponível em: https://doi.org/10.7476/9788575114698

BRAGANÇA, Ferreira de Souza. Curso de Pedagogia no Rio de Janeiro após Diretrizes Curriculares Nacionais: Políticas de Conhecimento e Formação. Educação e Cultura Contemporânea, v.11, p.136 - 167, 2014.

BENJAMIN, Walter. Obras escolhidas: magia e técnica, arte e política. São Paulo: Brasiliense, 1993

BRASIL. Lei 11.738 de 16 de julho de 2008. Regulamenta a alínea "e" do inciso III do caput do art. 60 do Ato das Disposições Constitucionais Transitórias, para instituir o piso salarial profissional nacional para os profissionais do magistério público da educação básica. Brasília, 2008.

BRASIL. Lei no 9.394 de 20 de dezembro de 1996. Estabelece as Diretrizes e Bases da Educação Nacional. Brasília, 1996.

BRASIL. Ministério da Educação. Parecer Conselho Nacional de Educação Câmara de Educação Básica n $9 / 2009$. Estudo sobre a Lei do Piso Salarial. Brasília, DF, 2009.

BRASIL. Resolução CNE/CP n o 2, de 20 de dez̧embro de 2019.Define as Diretrizes Curriculares Nacionais para a Formação Inicial de Professores para a Educação Básica e institui a Base Nacional Comum para a Formação Inicial de Professores da Educação Básica (BNC-Formação). Brasília, 2019. 
BRASIL. Resolução No 2, de $1^{\circ}$. de julho de 2015. Define as Diretrizes Curriculares Nacionais para a formação inicial em nível superior (cursos de licenciatura, cursos de formação pedagógica para graduados e cursos de segunda licenciatura) e para a formação continuada. Brasília, 2015.

BRASIL. Lei no 10.172, de 9 de jan. de 2001. Aprova o Plano Nacional de Educação e dá outras providências. Diário Oficial [da República Federativa do Brasil], Brasília, DF, 10 jan. 2001, p. 1. Disponível em: http://www.planalto.gov.br/ccivil_03/leis/leis_2001/110172.htm. Acesso em: 10 agosto. 2021.

BRASIL. Lei no 13.005, de 25 de junho. Aprova o Plano Nacional de Educação - PNE e dá outras providências, 2014. [Disponível em: http://www.planalto.gov.br/ccivil 03/ Ato20112014/2014/Lei/L13005.htm, acesso em: 15/07/15]. Acesso em: 10 agosto. 2021.

CAMARGO, Ana Maria Faccioli; FRACALANZA, Dorotéa Cuevas. Uma proposta de articulação entre o Instituto de Biologia, a Faculdade de Educação e a Escola de 2o Grau. In: PETRUCCI-ROSA; Maria Inês; ZAN, Dirce Djanira Pacheco. O campo da educação nos currículos das licenciaturas: princípios e práticas Campinas, SP: FE/UNICAMP, 2015.

CERTEAU, Michel. A invenção do cotidiano: artes de fazer. Petrópolis: Vozes, 1988.

CONSELHO ESTADUAL DE EDUCAÇÃO DE SÃO PAULO (CEE/SP). Deliberação CEE $n^{\circ}$ 126/2014. Altera dispositivos da Deliberação 111/2012. São Paulo, 2014.

CONSELHO ESTADUAL DE EDUCAÇÃO DE SÃO PAULO (CEE/SP). Proposta de alterações da deliberação CEE n 111/2012. Fixa Diretrizes Curriculares Complementares para a Formação de Docentes para a Educação Básica nos Cursos de Graduação de Pedagogia, Normal Superior e Licenciaturas, oferecidos pelos estabelecimentos de ensino superior vinculados ao sistema estadual. São Paulo, 2012.

DEMARTINI, Zeila de Britro Fabri; ANTUNES, Fátima Ferreira. Magistério primário: profissão feminina, carreira masculina. Cadernos de Pesuquisa, n. 86, p. 5-14, 1993. http://publicacoes.fcc.org.br/index.php/cp/article/view/934/939

FACULDADE DE EDUCAÇÃO. Para uma política de estágios da faculdade de educação. Campinas: UNICAMP, 2008.

FACULDADE DE EDUCAÇÃO. Projeto político pedagógico do curso de Pedagogia. Campinas: UNICAMP, 2017.

FERRAÇO, Carlos Eduardo; SOARES, Maria da Conceição Silva; ALVES, Nilda. Michel de Certeau e as pesquisas nos/dos/com os cotidianos em educação no Brasil. Pedagogia y saberes, v. 42, p. 7-17, 2017. Disponível em: https://revistas.pedagogica.edu.co/index.php/PYS/article/view/5224/3996

FREIRE, Paulo. Pedagogia da esperança: um reencontro com a pedagogia do oprimido. Rio de Janeiro: Paz e Terra, 1992.

GARCIA, Regina Leite (Org.). Para quem pesquisamos. Para quem escrevemos: o Impasse dos intelectuais. São Paulo: Cortez, 2001.

GODOY, Heliton Leite de (Org.). Diretrizes Curriculares da Educação Básica para o Ensino Fundamental - Anos Iniciais: Um processo Contínuo de Reflexão e Ação. Prefeitura Municipal de Campinas, Secretaria Municipal de Educação, Departamento Pedagógico. Campinas, SP, 2012. 
GONÇALVES, Nadia Gaiofatto; MONTEIRO, Ana Maria Ferreira da Costa. Saberes e práticas docentes e ensino de história: temas, conceitos e referenciais (1970-2014). Educação em Revista, Belo Horizonte, n.33, 2017.

GRAMSCI, Antônio. A concep̧ão dialética da História. Rio de Janeiro: Brasiliense, 1991.

JOSSO, Marie-Christine. Experiências de vida e formação. Natal: EDUFRN; São Paulo: Paulus, 2010.

JOSSO, Marie-Christine. Histórias de vida e formação: suas funcionalidades em pesquisa, formação e práticas sociais. Revista Brasileira de Pesquisa (Auto)Biográfica, Salvador, v. 05, n. 13, p. 40-54, jan./abr. 2020. < $\underline{\text { https://www.revistas.uneb.br/index.php/rbpab/article/view/8423/5390> }}$

KRAMER, Sonia. Propostas pedagógicas ou curriculares: Subsídios para uma leitura crítica. Educação \& Sociedade, ano XVIII, no 60, dezembro/1997. < $\underline{\text { https://www.scielo.br/pdf/es/v18n60/v18n60a1.pdf }>~}$

LARROSA, Jorge. Tremores: escritos sobre experiência. Belo Horizonte: Autêntica, 2017.

LINHARES, Célia F. S. A invenção da Escola Pública: o legado das vozes e das letras na formação dos professores. Universidade Federal Fluminense, Faculdade de Educação, Niterói, 1996.

LOURO, Guacira Lopes Louro. Mulheres na Sala de Aula. In: PRIORI; Mary Del Priore; BASSANEZI, Carla (Org.). História das mulheres no Brasil. São Paulo: Contexto, 2004.

MARINAS, José Miguel. La escuchaenlahistoria oral: palavra dada. Editorial Síntesis, 2007.

MARTINS, Renata Montanhaur. Narrativa - Estágio Supervisionado II - Anos Iniciais do Ensino Fundamental. Graduação em Pedagogia, FE/UNICAMP, 2021. Não publicado.

MATSUGUMA, Karina Yuki. Contribuições da narrativa (auto)biográfica para a formação docente inicial $e$ continuada: uma perspectiva feminista, antirracista e decolonial. Trabalho de Conclusão de Curso. FE/UNICAMP, 2020.

MEDEIROS, Caroline Carneiro. Formação continuada de professores na rede estadual e municipal de campinas: contribuições da abordagem narrativa (auto)biográfica. Relatório final de iniciação científica, UNICAMP/CNPq, 2019.

NOVO, Laura Fontana. Narrativa - Estágio Supervisionado II - Anos Iniciais do Ensino Fundamental. Graduação em Pedagogia, FE/UNICAMP, 2021.

NÓVOA, António; FINGER, Matthias (Org.). O método (auto)biográfico e a formação. Natal: EDUFRN; São Paulo: Paulus, 2010.

OLIVEIRA, Dalila de Andrade. Políticas conservadoras no contexto escolar e autonomia docente.Práxis Educativa, v. 15, p. 1-18, 2020. < https://www.revistas2.uepg.br/index.php/praxiseducativa $>$

PASSEGGI, Maria da Conceição; BARBOSA, Tatyana Mabel Nobre (Org.). Memórias, memoriais: pesquisa e formação docente. Natal: EDUFRN; São Paulo: Paulus, 2008.

PETRUCCI-ROSA; Maria Inês; ZAN, Dirce Djanira Pacheco. O campo da educação nos currículos das licenciaturas: princípios e práticas Campinas, SP: FE/UNICAMP, 2015.

PINEAU, Gaston. A autoformação no decurso da vida: entre a hetero e a ecoformação. In: NÓVOA, António; FINGER, Matthias (Org.). O método (auto)biográfico e a formação. Natal: EDUFRN; São Paulo: 
Paulus, 2010, p. 97-118.

PINEAU, Gaston. Ancoragem de uma política de pesquisa em ciências humanas: histórias das novas profissões socioeducativas em formação. Revista Brasileira de Pesquisa (Auto)Biográfica, Salvador, n. 13, p. 55-70, jan./abr. 2020.<DOI:http://dx.doi.org/10.31892/rbpab2525-426X.2020.v5.n13.p55-70>

PRADO, Guilherme do Val Toledo; CUNHA, Renata Cristina O. Barrichelo; SOLIGO, Rosaura. Memorial de formação: uma narrativa pedagógica de profissionais da educação. In: PASSEGGI, Maria da Conceição; BARBOSA, Tatyana Mabel Nobre (Org.). Memórias, memoriais: pesquisa e formação docente. Natal: EDUFRN; São Paulo: Paulus, 2008, p.135-152.

PRADO, Guilherme do Val Toledo; PROENÇA, Heloísa Helena Dias Martins; SERODIO, Liana Arrais; FILHO, Ruy Braz da Silva. Pipocas pedagógicas: uma possibilidade de narrar o vivido na escola. In.: (Orgs.). Pipocas pedagógicas IV : narrativas outras da escola. São Carlos: Pedro \& João Editores, 2017, p.9-22.

RÉ, Larissa Denny. Formação inicial e continuada de professoras/ es: diálogos, narrativas e reflexões partilhadas. Trabalho de Conclusão de Curso. Graduação em Pedagogia, FE/UNICAMP, 2020.

RICOEUR, Paul. Tempo e narrativa. Campinas: Papirus, 1994. t. 1.

ROSA, João Guimarães. Grande sertão: veredas. RJ: Nova Fronteira, 2006.

SME CAMPINAS. Resolução SE 72, de 16-12-2019. Dispõe sobre a carga horária dos docentes da rede $\begin{array}{llll}\text { estadual de } & \text { Campinas, } & 2019 .\end{array}$ http://siau.edunet.sp.gov.br/ItemLise/arquivos/72 19.HTM?Time=17/01/2020\%2010:17:50

SME CAMPINAS. Resolução SE 76/2020. Altera a Resolução SE 72, de 16-12-2019, que dispõe sobre a carga horária dos docentes da rede estadual de ensino. Campinas, 2020.

SOUZA, Elizeu Clementino. O conhecimento de si: narrativas do itinerário escolar e formação de professores. Tese (Doutorado em Educação). Salvador: Universidade Federal da Bahia, 2004.

SUÁREZ, D. H. Relatos de experiencia, saber pedagógico y reconstrucción de la memoria escolar. Educação em Revista, Belo Horizonte, n.01, p.387-416, 2011. $<\underline{\text { https://www.scielo.br/pdf/edur/v27n1/v27n1a18.pdf }>\text {. }}$

TARDIF, Maurice. Saberes profissionais dos professores e conhecimentos universitários. Revista Brasileira $\begin{array}{lllll}\text { de Educação, } & \mathrm{n}^{\circ} & 13, & \text { p. } & \text { 5-24, }\end{array}$ 2000. < http://www.ergonomia.ufpr.br/Metodologia/RBDE13 05 MAURICE TARDIF.pdf>

VARANI, Adriana.; ZAN, Dirce; GRANDIN, Luciane. O Curso de Pedagogia entre Deliberações. Revista Educação. Santa Maria, v. 45, 2020. https://periodicos.ufsm.br/reveducacao

VILELA, Heloisa. A primeira escola normal do Brasil. In: NUNES, Clarice (Org.). O passado sempre presente. SP: Cortez, 1992. 
